\title{
OBSERVATIONS ON THE TRANSPARENCY OF THE CONJUNCTIVA*
}

\section{BY}

\author{
Squadron Leader P. A. GARDINER, \\ R.A.F.V.R.
}

Introduction.-The aim of the present paper is to define some of the normal appearances of the conjunctiva, and to elucidate if possible, the causes of deviations from the normal, with particular reference to the part nutrition might play.

The investigation consisted of the examination with the slitlamp of large numbers of subjects of both sexes, of different nationalities, living in different climatic conditions and on differing diets. Thé age range of the subjects examined was from 9 years to 37 years. Experiments were performed on several groups of subjects.

Method of Examination.-The anterior half of the nasal and temporal segments of the interpalpebral bulbar conjunctiva was examined with the slit-lamp in every subject. The examination was directed mainly to the deeper layers of the conjunctiva, but comparatively gross changes in the epithelium were noted.

A wide beam was used and the light was arranged to be slightly 8 out of focus so that a bright diffuse illumination was obtained without interference from dazzling reflections and high lights.

The conjunctiva was examined with the eye turned away from? the segment concerned. If the temporal segment was being examined, the eye was turned nasally, and vice versa. This put the, conjunctiva on the stretch and evened out folds and depressions.

Examination of the conjunctiva in this manner showed that its transparency varied widely in different individuals, and it is with this variation that these observations are mainly concerned. The transparency was assessed by noting the relative visibility of the deep vessels lying on the sclera. In many subjects the transparency of the conjunctiva was affected by the presence of pingueculae or by diffuse hyaline degenerations. In these subjects, the area involved in the degeneration was ignored and the transparency of the surrounding unaffected part was recorded.

Method of Recording Results.-It was found that three degrees of opacity could be recognised quite easily. In some subjects the deep vessels could not be seen or could only be seen with great difficulty. The conjunctiva -in these subjects was termed opaque. In other subjects in whom the finest deep vessels could 
be seen with great ease the conjunctiva was termed clear. The term opalescent was used for intermediate degrees of opacity in which the large vessels could be seen easily and the small with difficulty or not at all. A combination of opaque and opalescent, or of opalescent and clear patches, occurred frequently in the area of conjunctiva that was examined.

In every subject, four segments of the conjunctiva were examined and a numerical system of classifying the appearances was devised. Each segment examined was given a type number according to its degree of transparency. The total for all four segments was taken to represent the relative degree of transparency of the conjunctiva for the particular individual and was termed the " conjunctival score."

The types were designated as follows :-

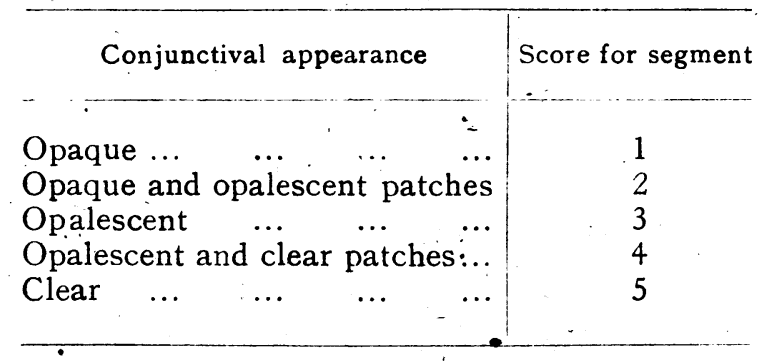

Foúr opaque segments would therefore be represented by a score of 4 and four clear segments by a score of 20 . These two scores represent the limits of opacity and transparency and all other degrees fall between them.

This method of scoring enabled comparisons to be made between individuals and also between groups of subjects.

Results.-Before reporting and analysing the main results a note should be made that throughout the large number of subjects examined, some of whom were shown to be deficient in vitamin " A " by. measurement of their dark adapted rod threshold, not one Bitot's spot was seen, nor any appearance suggestive of early xerosis. It has already been stated that the subepithelial tissues were the chief object of scrutiny and that the epithelium received little attention apart from the recording of relatively obvious changes. Fine epithelial changes may therefore have been present in some subjects.

Table I and Graph I show the distribution of men, women and children according to their conjunctival score. The individuals were unselected, but the totals as a whole are made up from groups which were selected. 
TABLE I

Distribution of Conjunctival Scores

\begin{tabular}{l|r|r|r}
\hline Score & Men & Women & Children \\
\cline { 3 - 4 } 4 & 134 & 5 & 88 \\
5 & 59 & 8 & 74 \\
6 & 107 & 7 & 122 \\
7 & 63 & 17 & 88 \\
8 & 145 & 33 & 64 \\
9 & 95 & 39 & 40 \\
10 & 147 & 45 & 43 \\
11 & 105 & 39 & 40 \\
12 & 239 & 30 & 13 \\
13 & 114 & 38 & 13 \\
14 & 141 & 34 & 14 \\
15 & 80 & 39 & 3 \\
16 & 126 & 22 & 4 \\
17 & 60 & 22 & 1 \\
18 & 88 & 18 & 1 \\
19 & 40 & 17 & - \\
20 & 149 & 21 & - \\
\hline Total & $\cdot 1,892$ & 434 & 591 \\
Mean & $11 \cdot 86$ & $11 \cdot 75$ & $7 \cdot 26$ \\
\hline
\end{tabular}

The groups were selected in the sense that the individuals in the group may have been doing similar work, or they may have been on the same diet or living in the same town. This is impossible to avoid. Each group, however, differed from the others

\section{GRAPH I}

COMPARATIVE INCIDENCE OF OPAQUE AND TRANSPARENT CONJUNCTIVAE IN NDULTS AND CHILDREN
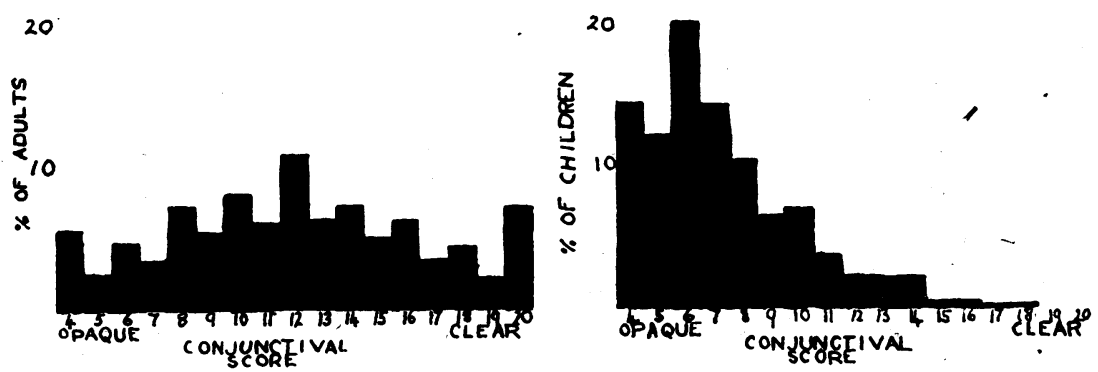
and as a large number of groups are included in the total, it can be said that they are fairly representative of a cross-section of normal healthy subjects.

The children were living a norm. 2 home and school life, and are representative of medium and low income groups.

One fact stands out from this table and graph. Every, degree of transparency is represented in the adults, but in the children the higher scores are very much fewer and in fact the highest are not reached at all. Their mean score is also much lower than the adults. It is apparent that age may be an important factor in the appearance of the conjunctiva.

Discussion of Results.-Table I and Graphs I and II show conclusively that the conjunctiva in the areas examined becomes progressively more transparent between the ages of 9 and 37 years. It is quite possible that this process begins before the age of 9 years. It is, however, impossible to record by this method, an increase in opacity beyond that which obscures the deep vessels. In addition, the examination of younger children with the slitlamp becomes increasingly difficult:

At the other end of the scale a high proportion of the subjects aged 37 years have transparent conjunctivae. It is probable that complete transparency is more nearly an absolute measurement by this method of examination than complete opacity and therefore that the process underlying the appearance is complete about the age of 40 years. The latter conclusion should, however, be treated with reserve.

It has been stated that as age advances the conjunctiva becomes less transparent than in children (Duke-Elder, 1938). This refers apparently to layers in the epithelium and to the appearances of hyaline degeneration and pingueculae. The present investigation showed that it was common to find pingueculae and hyaline changes surrounded by completely transparent conjunctiva in the older age groups. Examination with the slit-lamp produced no evidence that the degeneration of a hyaline nature was taking place in these transparent areas. Microscopic examination would be necessary to confirm this.

It has also been stated that there is an atrophy of the subepithelial layers with increasing age (Wilmer, 1929). The increase in transparency that has been found in the present investigation is probably due to this atrophy. This is borne out by the observation that a completely transparent conjunctiva in older subjects appears to rest directly on the sclera with no interyening tissue whatever. In addition a child's conjunctiva is felt to be thicker than an adult's when it is held between forceps.

Study of Graph II shows that the rate of increase in transparency varies at different ages. It is about half as rapid in the lower and 
higher age groups as it is between 17 and 29 years. The difficulty already mentioned in measuring opacity in young children must, be remembered, and if this is taken into account it is possible that the rate is more or less constant until complete transparency is reached. Other factors which may influence the rate of change will he discussed later.

The conclusion arrived at, therefore, is that it is a normal phenomenon for the areas of bulbar conjunctiva unaffected by hyaline changes to increase in transparency between the ages of 9 and 37 years.

\section{GR R PH II}

INCREASE IN TRANSPARENCY OF THE CONUUNCTIIVA. WITH INCREASING AGE

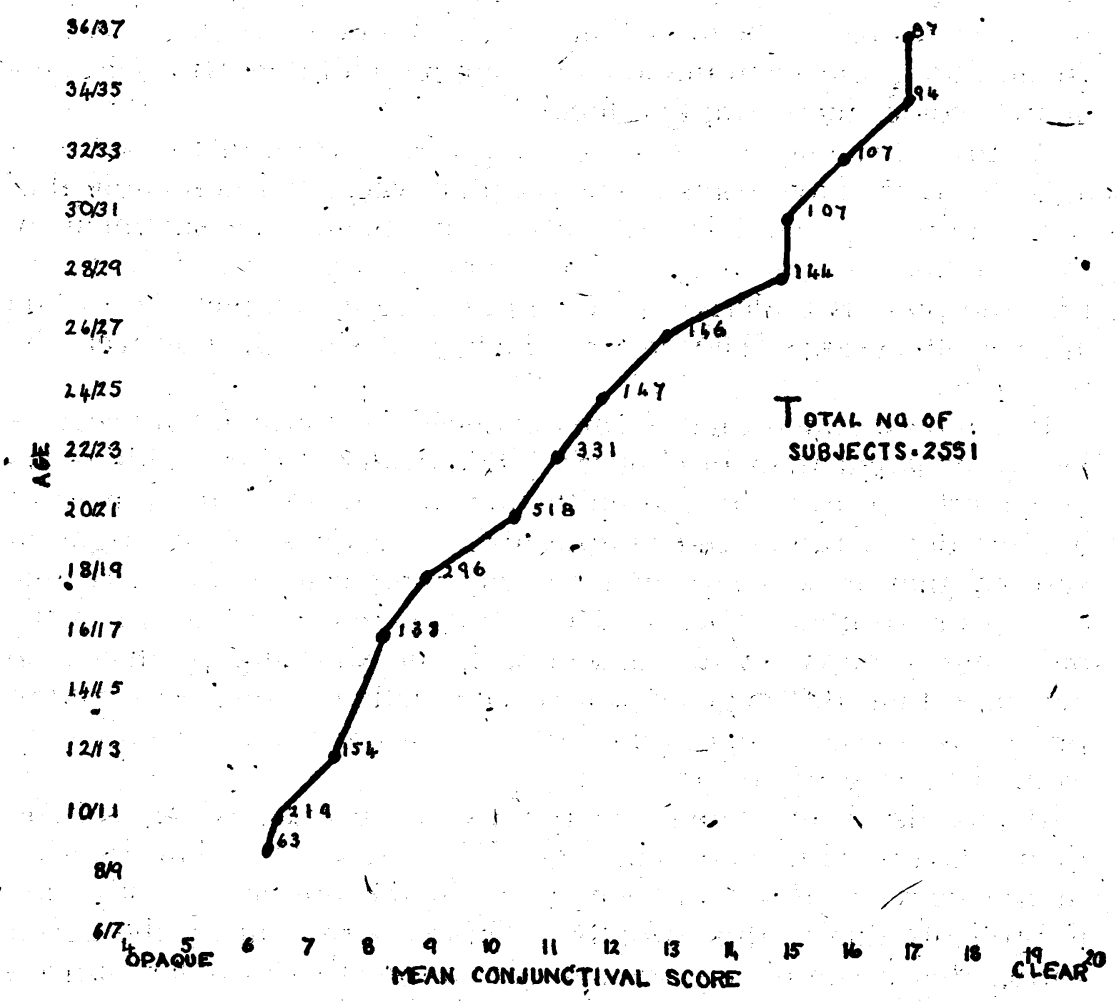

Age Changes. Graph II shows the correlation between age and the degree of opacity of the conjunctiva. The mean conjunctival score has been plotted against the age concerned. There is an increase in transparency with increasing age throughout the whole age range examined. 


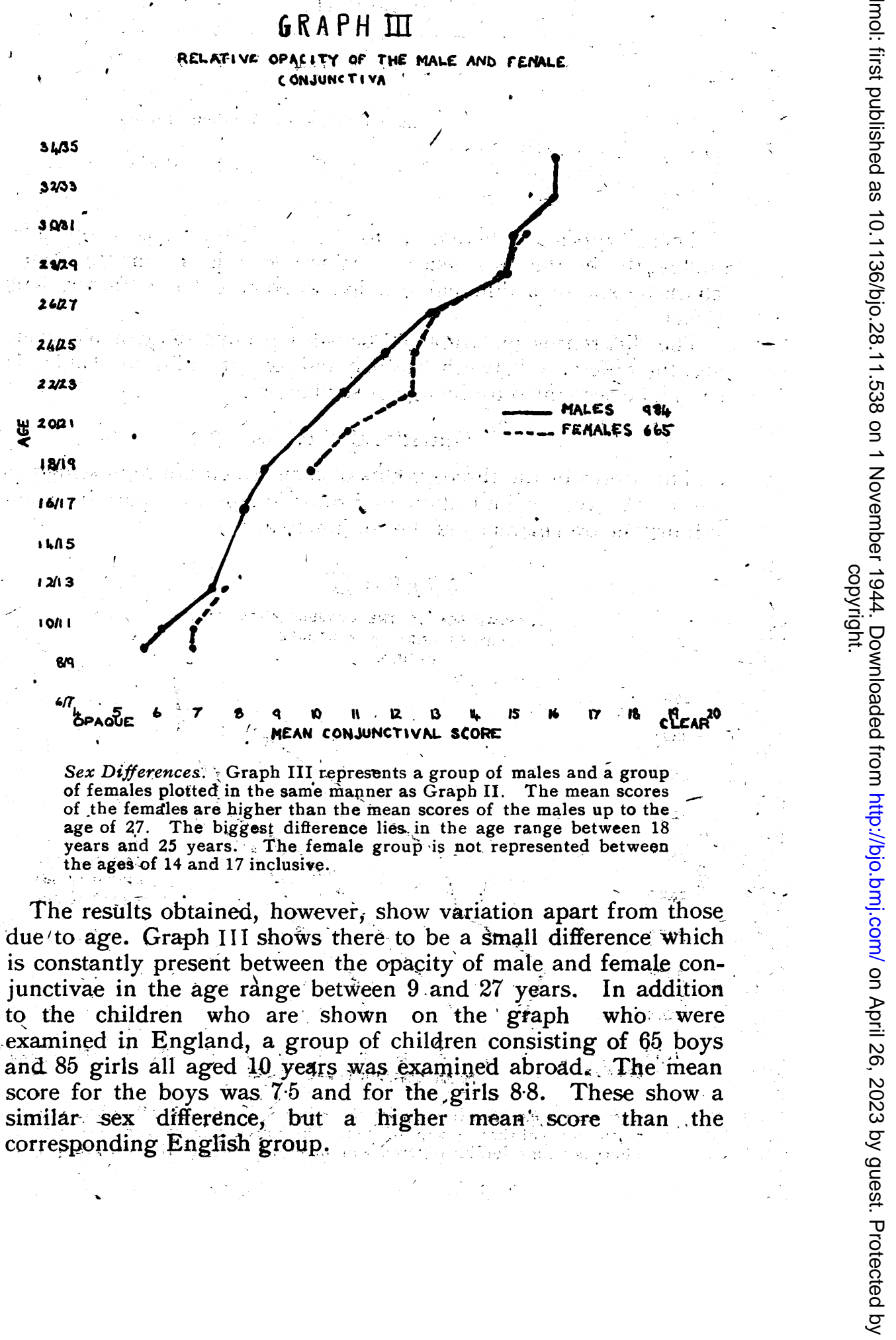


TABLE II

\begin{tabular}{cc|c|c|c|c}
\hline & \multicolumn{2}{|c|}{ Boys of Ten } & \multicolumn{2}{c}{ Girls of Ten } \\
\cline { 2 - 5 } & English & Foreign & English & Foreign \\
Mean conjunctival & & & \\
score $\ldots$ & $\ldots$ & 6.2 & 7.5 & $7 \cdot 0$ & 8.8 \\
\hline
\end{tabular}

There appears, therefore, to be a factor which operates differently in the two sexes. Whether it is an innate sexual characteristic or a different reaction to some external factor, it is difficult to say.

The differences in Graph IV between groups of men however, and the difference between English and foreign children (Table II) cannot be accounted for by age or sex factors.

\section{Nutritional Factors}

The scores of the three groups of men which are represented in Graph IV give an indication that nutrition plays a part in determining the transparency of the conjunctiva.

$$
\begin{gathered}
\text { GRAPH D } \\
\text { COMPARISON OF THE CONJUNCTIVAL } \\
\text { TRANSPARENCY IN } 3 \text { GROUPS } \\
\text { OF MEN }
\end{gathered}
$$
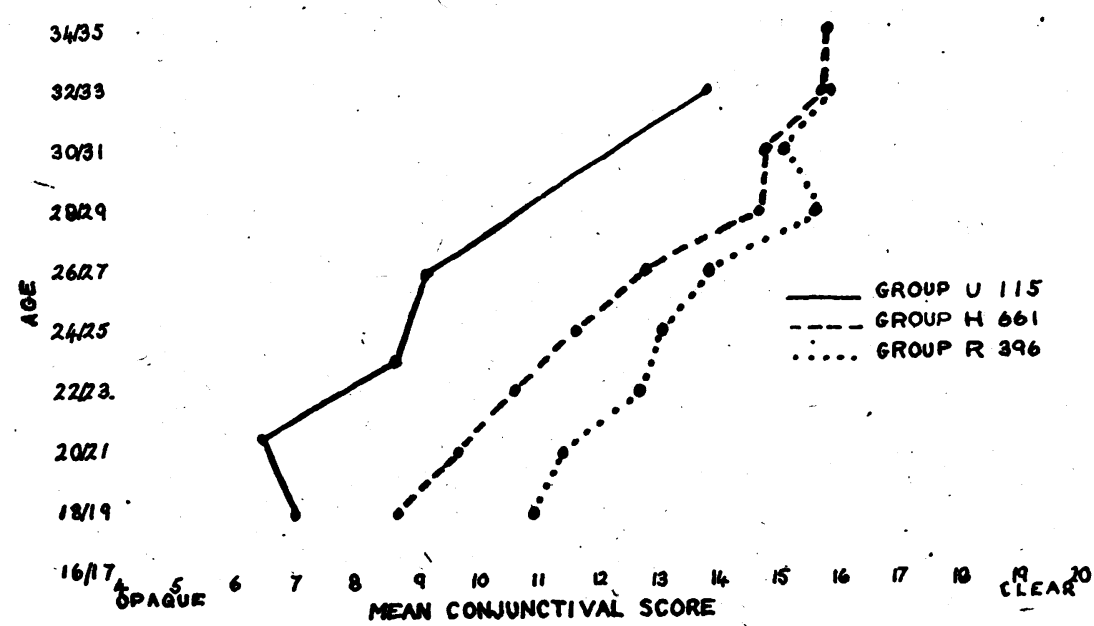

Differences between Groups of the same Sex. Graph IV shows the mean scores of three groups of men. The individuals were not selected. There is a considerable difference in the mean scores of all these groups. 
Statistical Analysis.

a. Graph II. The standard deviation of Graph II varies between 2.03 and 3.90 and the standard error of the various means varies between \pm 0.14 and \pm 0.32 . The lower of these figures is amongst the children and the higher in the age group 26/27 years where there is a wider spread of scores.

b. Graph III. The difference between the recorded means is more than three times the standard $\epsilon$ rror of the difference at the ages $10 / 11$ years and at $22 / 23$ years. Age is ruled out as a factor in the two groups because a common age is used for comparison.

$\mathrm{X}^{2}$ applied to the age groups $18 / 25$ years in the two curves gives $\mathrm{P}=<0.01$. The age distribution is such that the females in this age range have a mean age of 21.51 years and the males 21.68 years. There is therefore very little difference in age distribution between the two groups and the significant difference is likely to be due to a factor other than age.

There is no significant difference between the groups above the age of 25 years.

c. Graph IV. At the age 20/21 years the difference in mean scores between all three groups is more than three times the standard error of the difference. At the age of 26/27 years the difference between groups $U$ and $H$, and $U$ and $R$ is similarly significant. The difference between groups $H$ and $R$ at this age is not significant.

- $\mathrm{X}^{2}$ shows that $\mathrm{P}=<0.01$ for the differences between all three curves in the age range 18/25 years. Over 25 years $\mathrm{P}=<0.01$ for the differences between $H$ and $U$, and $U$ and $R$, but not between $H$ and $R$. The mean ages of the three groups $U, H$ and $R$ in the age range $18 / 25$ years are respectively $21.24,21.68$ and 21.51 years. The difference between group $U$ and the other two might therefore be due to the age distribution but the significant difference found in the age group 20/21 years negatives this possibility in this age group.

Groups $U$ and $R$ were of different race but for 9 months had been living and working in the same climate and apart from their diet were living under similar conditions. Group $\mathrm{H}$ was of the same race as group $R$ but on a different diet from both $U$ and $R$ and working in a different country. Group $U$ had a far better diet than group $\mathrm{R}$ which had the worst diet of the three. Up to 9 months before the examination groups $H$ and $R$ had had a similar diet. The most striking differences in the diets were the presence of relatively large quantities of milk, vegetables and fruit juice in the diet of group $U$ as compared with group $R^{\prime}$ and the high proportion of preserved food in the diet of group $R$ compared with the other two. 
On the whole, the dietary history as far as it could be ascer- tained can be said to have been good in group $U$ throughout, fair in group $H$ and fair in group $R$ until 9 months previous to the examination, when it became poor.

It would appear therefore; that a poor diet is accompanied by a relatively transparent conjunctiva; and a good diet by a relatively opaque conjunctiva. If there is any causal connection between the two, the change can occur in 9 months.

TABLE III

Relation between conjunctival transparency and corneal vascularisation .

ADults

\begin{tabular}{|c|c|c|c|}
\hline \multirow{2}{*}{$\begin{array}{c}\text { Conjunctival } \\
\text { Score }\end{array}$} & \multicolumn{3}{|c|}{ Mean Limbal Score } \\
\hline & \multicolumn{2}{|c|}{ Group R } & Group U \\
\hline $\begin{array}{r}4-8 \\
9-12 \\
13-16 \\
17-20\end{array}$ & $\begin{array}{c}\text { Under } 26 \text { years } \\
8^{\circ} 5 \\
9.2 \\
11^{\circ} 1 \\
10^{\circ} 9\end{array}$ & $\begin{array}{c}\text { Over } 26 \text { years } \\
84 \\
8.8 \\
114\end{array}$ & $\begin{array}{r}95 \\
97 \\
112\end{array}$ \\
\hline
\end{tabular}

TABLE IV

Relation between conjunctival tratisparency aud corneal vascularisation

CHILdREN -

\begin{tabular}{|c|c|}
\hline Conjunctival Score & Mean Limbal Score \\
\hline $\begin{array}{r}4 \\
5 \\
6 \\
-7 \\
8 \\
9 \\
\text { over } 9\end{array}$ & $\begin{array}{r}8.5 \\
92 \\
9.2 \\
92 \\
94 \\
10^{\circ} 5 \\
10^{\circ} 9\end{array}$ \\
\hline
\end{tabular}

Corneal vascularisation is indicative of nutritional deficiency (Sydenstricker V.P. et al., 1940). A correlation has been obtained between the appearance of the conjunctiva in a group of subjects 
and the degree of vascularisation of the cornea. A numerical system of classifying the degree of vascularisation of the limbus and cornea has been devised (to be published). It suffices to say that the higher the "limbal score" the more the cornea is vascularised.

Both Tables III and IV show that an increased conjunctival score is accompanied by an increased mean limbal score.

\section{TABLE V}

Relationship of conjunctival appearances to signs of nutritional deficiency

\begin{tabular}{c|c|c|c}
\hline Group & $\begin{array}{c}\text { Percentage of Subjects } \\
\text { under 26 years with } \\
\text { Con jun ctival Score } \\
\text { over 12 }\end{array}$ & $\begin{array}{c}\text { Mean Dark Adapted Rod } \\
\text { Threshold of Subjects } \\
\text { under 26 jears } \\
\text { (Log } \mu \mu 1)\end{array}$ & $\begin{array}{c}\text { Percentage of } \\
\text { Subiects with } \\
\text { Corneal Vas- } \\
\text { cularisation }\end{array}$ \\
\hline 1 & 53 & 3736 & 16.5 \\
2 & 42 & 3787 & 4 \\
3 & 38 & 3663 & 4 \\
4 & 32 & 3710 & 3 \\
5 & 24 & 3730 & 6 \\
6 & 20 & 3694 & 15 \\
7 & 11 & 3627 & 0 \\
8 & 9 & 3710 & \\
\hline
\end{tabular}

Table $\mathrm{V}$ shows several groups of subjects who were examined for corneal vascularisation and also for changes in their dark adapted rod threshold. A rise in the latter may be indicative of vitamin " A " deficiency (Yudkin, S,, 1941), and it is presumed that any groups showing raised mean thresholds would be likely to have other nutritional deficiencies in some degree since a pure vitamin " A" deficiency is not likely to be found except under experimental conditions.

In order to overcome the marked influence of age and also to avoid confusing graphs, the proportion of men under 26 years who had conjunctival scores over 12 in each group are shown with the mean dark adapted rod thresholds and the proportion of subjects with corneal vascularisation."

It will be seen from this table that there is a rough correspondence between a high incidence of corneal vascularisation, high values of the mean rod threshold and a high incidence of transparent conjunctivae.

The climate and general working conditions were similar in 
each group but their diets differed. The worst diet was being received by group 1 and the best by group 7 .

\section{Experimental Results}

Vitamin "A," ascorbic acid, riboflavin, and a diet containing large amounts of liver have all been tried in an endeavour to find a specific nutritional factor which might influence the transparency of the conjunctiva. Two groups of men were given a variety of high quality food supplements in their diet.

The general plan of all the experiments was similar. The conjunctivae of the groups of subjects concerned were examined with the slit-lamp before and after the administration of the particular nutrient concerned.

The number of subjects whose score altered between each examination, and the degree of alteration, was recorded. In this way a tendency in the group towards increased trànsparency or opacity could be demonstrated.

In order to make the wider changes more obvious, subjects with a change in score of \pm 2 have been recorded with the subjects who show no change in the following tables.

Vitamin "A." $-50,000$ I.U. of vitamin " A " were administered daily to a group of men for three weeks. They were on a poor diet otherwise, and measurement of their dark adapted rod thresholds gave a very high mean value.

TABLE VI.

Changes in Conjunctival Score

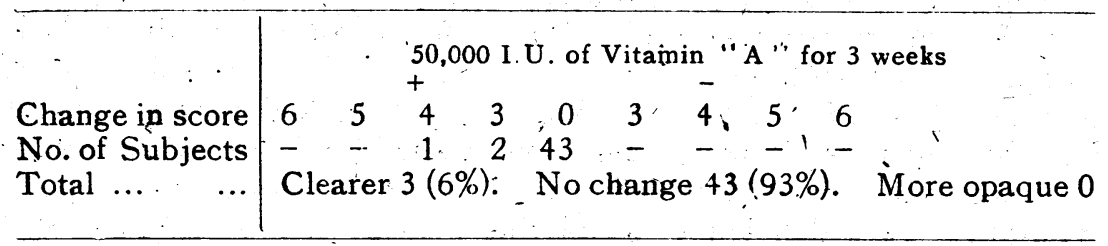

Riboflavin.-A group of men was given $10 \mathrm{mg}$. of riboflavin daily for three weeks. The men were on a poor diet.

TABLE VIII

Changes in Score after riboflavin $\mathrm{mg}$. 10. for 3 weeks

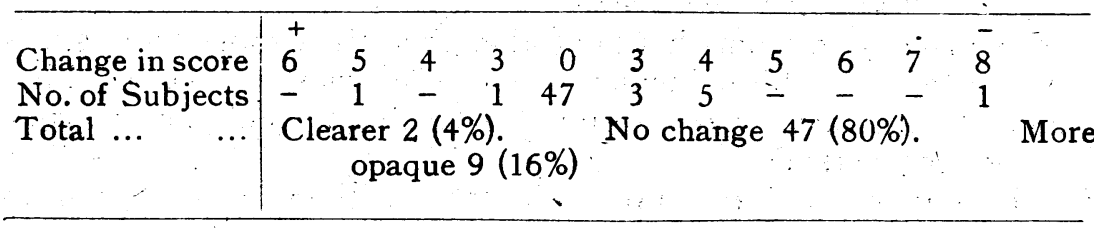


This shows that there was a small move in the direction of increased opacity. A subsequent experiment with riboflavin given to a group on a good diet failed to confirm this result.

$A$ scorbic Acid. $-\mathrm{A}^{-}$group of men was given approximately $4.5 \mathrm{gm}$. of ascorbic acid in two weeks. Previous to the administration of the tablets they were shown to be " unsaturated " with the vitamin.

TABLE VIII

Changes in Conjunctival Score

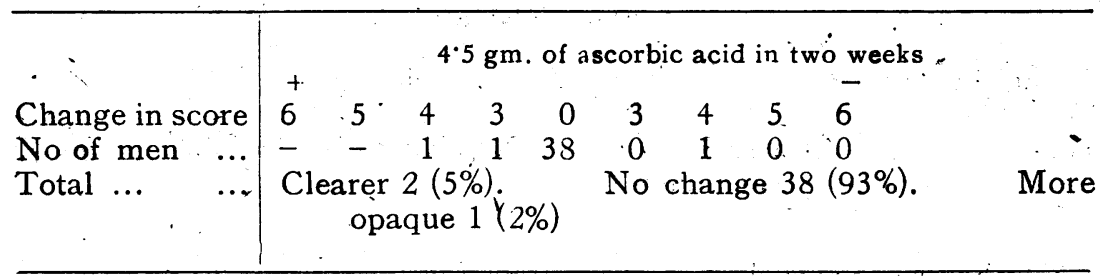

This table shows that no change in the conjunctiva occurred after ascorbic acid.

Liver.-A group of men was given approximately $\frac{1}{2} \mathrm{lb}$. liver per week for one month. They were on a good diet otherwise.

TABLE IX

Changes in Canjunctival Score

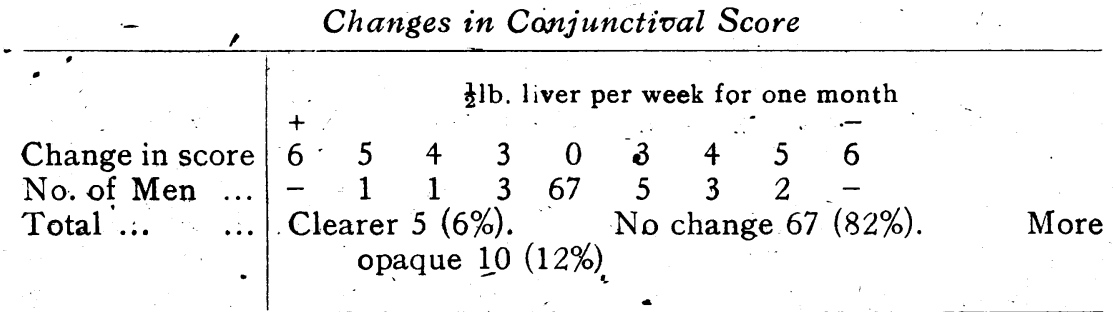

A small movement toward increased opacity occurred.

Food Supplementation.-A large group of men was given dried milk, dried eggs, dried vegetables, orange juice and food. yeast in addition to their ordinary diet for five weeks. They were on a fair diet otherwise.

TABLE X

Changes in Conjunctival Score

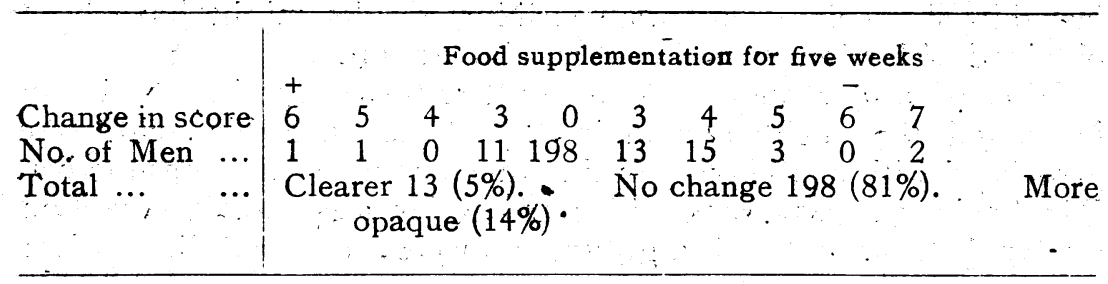


A small movement toward increased opacity occurred.

Control.-A control gróup was examined. These subjects were intermingled with one of the other groups and were examined at the same time. At the examination it was not known whether the subjects were in the control group or the treated group.

\section{"TABLE XI}

Changes in Conjunctival Score.

\begin{tabular}{|c|c|c|c|}
\hline & Dummy & tablets for one month & \\
\hline $\begin{array}{l}\text { Change in score } \\
\text { No. of Men } \ldots \\
\text { Total ... }\end{array}$ & $\begin{array}{lllll}6 & 5 & 4 & 3 & 0 \\
- & 2 & 2 & 4 & 100 \\
\text { Clearer } 8(7 \%) \\
\text { opaque } 8(7 \%)\end{array}$ & 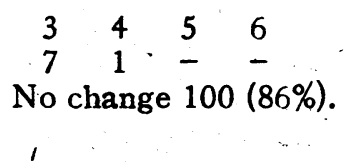 & More \\
\hline
\end{tabular}

No change occurred.

Table XII summarises these results.

\begin{tabular}{|c|c|c|c|c|c|c|}
\hline & \multicolumn{6}{|c|}{ Summary of Tables VI to XI } \\
\hline & \multicolumn{4}{|c|}{ FOOD FACTOR } & 、 & - \\
\hline lange observed & Control & Vitamin A & Riboflavin & $\begin{array}{c}\text { Ascorbic } \\
\text { Acid }\end{array}$ & Liver & $\begin{array}{l}\text { Food } \\
\text { Supt. }\end{array}$ \\
\hline $\begin{array}{l}\text { Clearer } \\
\text { No change } \quad \ldots \\
\text { More opaque... }\end{array}$ & $\begin{array}{c} \\
\text { pet cent. } \\
7 \\
86 \\
7\end{array}$ & $\begin{array}{c}\text { per.cent. } \\
6 \\
94 \\
0\end{array}$ & $\begin{array}{c}\text { per cent. } \\
4 \\
80 \\
16\end{array}$ & \begin{tabular}{|c} 
per cent. \\
5 \\
93 \\
2
\end{tabular} & $\begin{array}{c}\text { per cent. } \\
6 \\
82 \\
12\end{array}$ & $\begin{array}{c}\text { per cent. } \\
5 \\
81 \\
14\end{array}$ \\
\hline
\end{tabular}

Before discussing the significan e of these results, it must be pointed out that although a control group was examined, it was independent of any of the groups whose results are set out here. To some extent then, any deductions which are made should be taken with reserve. A second criticism is, that the experiments lasted a short time and more striking results might have beenobtained with a longer period of administration.

Discussion of Results.-As a result of these experiments, it can be stated that neither vitamin "A" nor ascorbic acid were associated with any change in the transparency of the conjunctiva. Riboflavin was associated with a change in a group. who were on a poor diet, but not with a group who were on a good diet. Liver 
and also food supplementation with a variety of nutrients appeared to have an effect. It is seen that in these three groups the conjunctiva became more opaque after the administration of the factor concerned.

Another fact emerged from the experiment with liver, which bears out the correlation of the conjunctival appearance with the degree of vascularisation of the cornea.

All those subjects whose conjunctival score increased by 4 or 'more, were selected, and the degree of vascularisation at the first ${ }^{-}$ and second examinations was noted. Table XIII shows the results obtained.

TABLE XIII

(a) Subjects whose Conjunctival Score increased by 4 or more

\begin{tabular}{c|c|c|c}
\hline $\begin{array}{c}\text { Corneal } \\
\text { Vascularisation }\end{array}$ & $\begin{array}{c}\text { Less } \\
\text { Marked }\end{array}$ & $\begin{array}{c}\text { No } \\
\text { Change }\end{array}$ & $\begin{array}{c}\text { More } \\
\text { Marked }\end{array}$ \\
\hline No. of Men & 4 & 3 & 10 \\
\hline
\end{tabular}

(b) Subjects whose Conjunctival Score increased less than 4. or decreased

\begin{tabular}{c|c|c|c}
\hline $\begin{array}{c}\text { Corneal } \\
\text { Vascularisation }\end{array}$ & $\begin{array}{c}\text { Less } \\
\text { Marked }\end{array}$ & $\begin{array}{c}\text { No } \\
\text { Change }\end{array}$ & $\begin{array}{c}\text { More } \\
\text { Marked }\end{array}$ \\
\hline No. of Men & 15 & 4 & 6 \\
\hline
\end{tabular}

The significance of these results is that increased transparency of the conjunctiva was associated with increased corneal vascularisation, and increased opacity of the conjunctiva was associated with decreased corneal vascularisation.

This adds to the evidence that there is some link between transparency of the conjunctiva and corneal vascularisation.

No increase in the number, or congestion of the deep conjunctival vessels has been seen in conditions of corneal vascularisation. An increase of the fine vessels at the limbus can hardly be directly linked with a change in the visibility of the deep conjunctival vessels, and it seems that a common extrinsic factor influences both appearances. 
The conclusions to be drawn from the whole series of experiments should be guarded. The results indicate that nutritional factors may play a part in influencing the transparency of the conjunctiva, but in view of the extreme variety in the quality of the diet received in the different groups, no conclusions as to the specificity of any one nutritional element should be drawn, especially in the absence of a firm control group.

Summary of the evidence for a nutritional factor.-A compara- tively high incidence of transparent conjunctiva at a given age is found in groups of subjects who are relatively poorly fed (Graph 4, Table V).

There is a correlation in groups of subjects between the degtee of corneal vascularisation and conjunctival transparency (Tables III, V, XIII).

There is a correlation in groups of subjects between a high incidence of transparent conjunctivae and a high incidence both of corneal vascularisation and of high mean values of their dark adapted rod thresholds. Both the latter phenomena are known to be the result of an inadequate diet (Table $V$ ).

High quality food supplementation and a diet containing large quantities of liver have been accompanied by a slight increase in conjunctival opacity in groups of subjects (Table XII).

In addition to these facts it is a reasonable supposition that - acceleration of a normal degenerative process is likely to be produced by a poor diet.

\section{Implications of the Results of the Investigation}

If the transparency of the conjunctiva is increased in malnutrition it is probably an early sign. As already mentioned group $\mathrm{R}$ had been having a bad diet for only nine months. Previously they had had a similar diet to group $\mathrm{H}$. In none of the groups examined were there any general signs of malnutrition such as loss of weight, etc., and the subjects were all apparently normal and healthy. It is suggested therefore, that surveys of groups of subjects for the early signs of malnutrition might usefully include an estimation of the conjunctival transparency. A difficulty arises in demarcating the limits of normality. The temptation to analyse changes too finely is constantly present. However, the graph published in this paper should assist in giving a basis for comparative studies (Graph 2):

It might be argued that if premature transparency is a sign of malnutrition, then only the graph representing the most opaque conjunctivae should be used for reference, namely group. $U$. This is not advised because it was a small, selected, homogeneous and 
foreign group, and it is sounder practice to base nórmality on a large mixed group until the standards have been further worked out.

The graph of 2,551 subjects (Graph 2 ) 'consists of men, women and children and is fairly representative of apparently healthy people. However, about a fifth of the subjects whose scores are shown in this graph come from groups with very high mean conjunctival scores. These subjects were on a poor diet and therefore the graph represents mean scores higher than a possible optimum opacity of the conjunctiva. Any group of subjects which shows consistently higher scores still should be regarded as being under suspicion of malnutrition. Allowances should be made for sex differences.

Clinically, a transparent conjunctiva in children particularly, and also in young adults should be regarded as abnormal and should lead to an investigation into possible dietary deficiency or metabolic disturbances. It must be stressed that a high magnification, a fairly wide field and a high illumination without bright reflections are necessary to be sure of consistent results.

\section{Conclusions}

1. The transparency of the interpalpebral bulbar.conjunctiva increased between the ages of 9 and 37 years in the absence of hyaline degenerative changes. In those subjects in whom hyaline degenerative changes were found, the areas which were spared showed increased transparency with age,

2 . The rate of change was most rapid between the ages of 17 and 30 years and was less at the two extremes of the age range examined.

3. The females examined shówed-a constantly more transparent conjunctiva than males between the ages of 9 and 27 years.

4. Nutritional factors probably play a part in influencing the transparency' of the conjunctiva. A good diet tends to increase opacity whereas a bad diet increases transparency between the ages of 9 and 37 years.

5. There was an association, probably through nutrition, between the transparency of the conjunctiva and increased vascularity of the limbus.

6. Slit-lamp examinations of the conjunctiva of a group of subjects enable deductions to be made as to the nutritional wellbeing of the group.

Acknowledgements.-I should like to thank Wing Commander T. Keith Lyle, and Squadron Leader Macrae, for their help and encouragement throughout.

Flight Lieutenant Yudkin tested the-dark adapted thresholds 
and I am indebted to him for this and for his participation in the rough and tumble of the investigation.

\title{
REFERENCES
}

DUKE-Elder, S. (1938)--Text-book of Ophthalmology. Vol. II, Henry Kimpton. Sydenstriker, V. P. (et al., 1940).-Jl. of Amer: Med. Assoo., Vol. CXIV, p. 2437.

WILMER (1929).-Arch. of Ophthal., Vol. I, p. 41.

YUDKIN, S. (1941).-Lancet ii, p. 787.

\section{PHOTOGRAPHS OF RETINAL DETACHMENT IN APHAKIA BEFORE AND AFTER OPERATION}

BY

\author{
EMANUel Rosen, \\ NEWARK, NEW JERSEY, U.S.A.
}

MRS. B. G., age 61 years, first came under my care May 9, 1939, because of progressive diminution of vision. The patient had a mild grade of diabetes associated with rather marked hypertension.

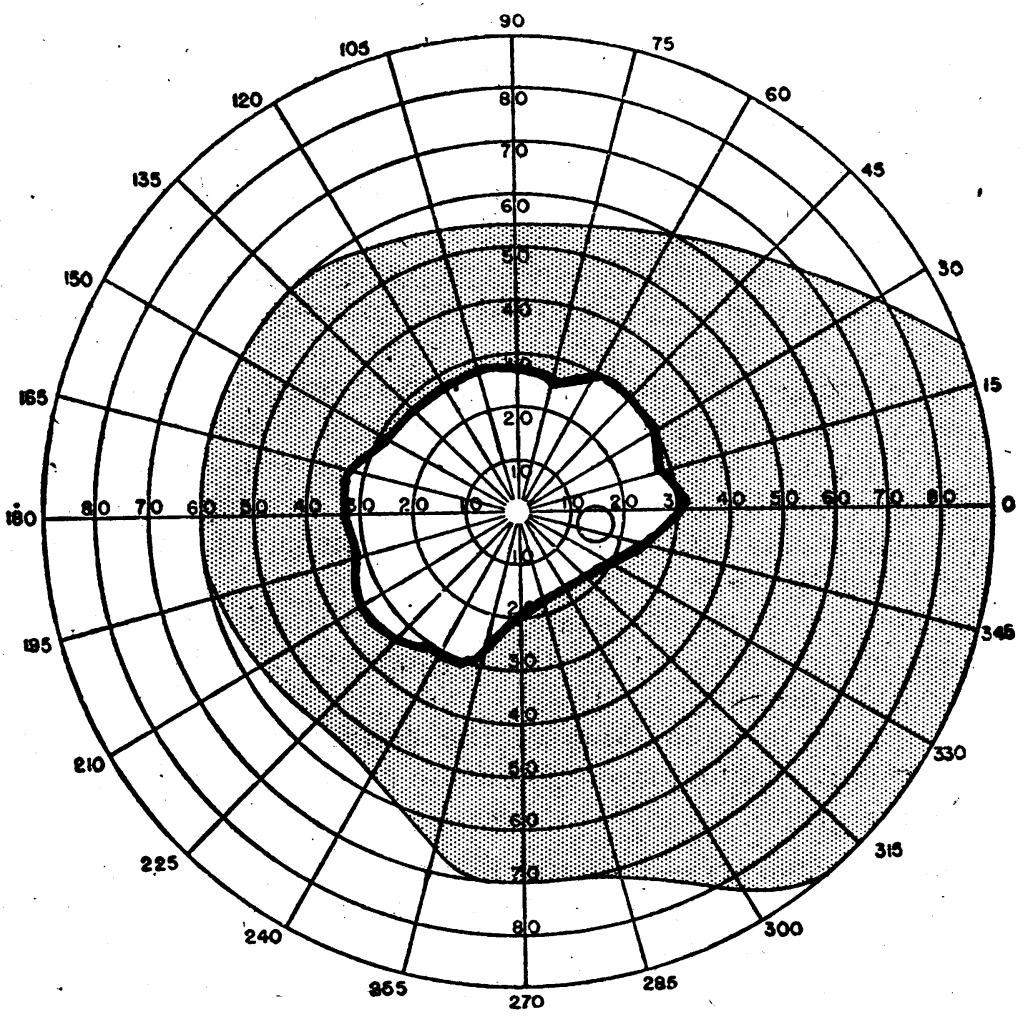

FiG. 2 . 